\title{
Cyclic performance of concrete-filled steel batten built-up columns
}

\author{
M. S. Razzaghi ${ }^{1} \cdot$ M. Khalkhaliha ${ }^{1} \cdot$ A. Aziminejad ${ }^{2}$
}

Received: 28 January 2016/ Accepted: 1 February 2016/Published online: 1 March 2016

(C) The Author(s) 2016. This article is published with open access at Springerlink.com

\begin{abstract}
Steel built-up batten columns are common types of columns in Iran and some other parts of the world. They are economic and have acceptable performance due to gravity loads. Although several researches have been conducted on the behavior of the batten columns under axial loads, there are few available articles about their seismic performance. Experience of the past earthquakes, particularly the 2003 Bam earthquake in Iran, revealed that these structural members are seismically vulnerable. Thus, investigation on seismic performance of steel batten columns due to seismic loads and providing a method for retrofitting them are important task in seismic-prone areas. This study aims to investigate the behavior of concretefilled batten columns due to combined axial and lateral loads. To this end, nonlinear static analyses were performed using ANSYS software. Herein, the behaviors of the steel batten columns with and without concrete core were compared. The results of this study showed that concrete-filled steel batten columns, particularly those filled with high-strength concrete, may cause significant increases in energy absorption and capacity of the columns. Furthermore, concrete core may improve post-buckling behavior of steel batten columns.
\end{abstract}

Keywords Steel batten columns - Buckling - Numerical analysis · Lateral loads

M. S. Razzaghi

razzaghi.m@gmail.com

Qazvin Branch, Islamic Azad University, Qazvin, Iran

2 Science and Research Branch, Islamic Azad University, Tehran, Iran

\section{Introduction}

During the past decades, several researches have concentrated on the performance of steel built-up batten columns due to axial loads (Hosseini Hashemi and Jafari 2009, 2012). Following the Bam earthquake of 2003 in southeastern Iran, several steel structures were damaged (Eshghi et al. 2003). Failure of the built-up batten columns was one of the most observable failure modes in damaged buildings (Hosseini Hashemi and Jafari 2004; Hosseinzadeh 2004). In most of these studies, the behavior of the batten columns due to gravitational loads was investigated. In other words, most of the researchers neglected the effect of the lateral loads on the behavior of steel batten columns (Hosseini Hashemi and Jafari 2004). Following the Bam earthquake, some studies were conducted to investigate the behavior of batten columns due to the earthquake. Razzaghi et al. (2010) investigated the performance of built-up batten columns due to axial and cyclic lateral loads. The results of this study revealed that laterally loaded batten columns had extremely unstable behaviors in the post-buckling region. It was also shown that existing code provisions are not sufficient for seismic design of batten columns. Furthermore, Hosseini Hashemi and Hassanzadeh (2008) studied the performance of the damaged steel building with batten columns due to the Bam earthquake.

Based on the seismic vulnerability of steel batten columns and the large number of buildings with these types of columns in areas with high seismic action potential, retrofit methods are required for steel batten columns. On the other hand, concrete-filled steel tubular columns are widely used in steel structures. Several numerical and experimental investigations revealed the acceptable performance of concrete-filled tubes under different loading conditions (Cai and He 2007; de Oliviera et al. 2010). Hence, it seems 
that filling the hollow space between column chords would be a suitable method for improvement of seismic performance of built-up batten columns.

This paper aims to investigate the performance of concrete-filled built-up batten columns (CFBBC) as both retrofitted columns and newly designed and/or constructed columns. To this end, nonlinear static analyses were performed using the ANSYS (SAS 2010) software. Herein, parametric studies on the effects of compressive strength of concrete, distances of batten plates and axial loads on the performance of CFBBC were conducted.

\section{Modeling}

To conduct a parametric study on the performance of axially and laterally loaded CFBBC, the finite element method was used. In all of the models, both material and geometric nonlinearities were considered.

\section{Geometric specifications of models}

Geometric specifications of steel batten columns were adopted from the columns of the ground floor of a building damaged in the Bam earthquake as reported by Hosseini Hashemi and Hassanzadeh (2008). The target building was of steel frame with an X-bracing system. The columns had two IPE 160 chords, $17 \mathrm{~cm}$ apart, and battened by $18 \times 10 \times 1 \mathrm{~cm}$ batten plates at a distance of $50 \mathrm{~cm} \mathrm{c} / \mathrm{c}$. The height of the ground floor was $5.2 \mathrm{~m}$. The geometric specifications of the models are summarized in Table 1. As indicated in Table 1, there are two main categories of models: columns without concrete cores and columns with concrete cores. It should be noted that for those column which were originally designed and fabricated as CFBBC, the axial loads would be distributed to concrete and steel according to their stiffness. Such distributions may not occur in retrofitted batten columns. Hence as indicated in the second column of Table 1, different distribution of axial loads are considered in CFBBC models.

\section{Elements used for FE analyses}

Three-dimensional solid elements (Solid 65) have been used to model the concrete core. This element is defined by eight nodes having three translational degrees of freedom at each node. This solid element is capable of cracking in tension and crushing in compression, plastic deformation and creep (SAS 2010). Three-dimensional solid elements (Solid 45) were used to model the steel batten columns. This element is defined by eight nodes having three translational degrees of freedom at each node. This element has suitable compatibility with the solid element of the concrete core. The element has plasticity, stress stiffening, large deflection and large strain capabilities (SAS 2010). Three-dimensional node to node contact element (Contact 178) was used to model the contact between the steel wall and concrete core. The element is located between two adjacent nodes of steel wall and the concrete core and is capable of modeling the separation, sliding and contact between two nodes during the loading process. The element has two nodes with three translational degrees of freedom at each node. The element is capable of supporting compression in the contact normal direction and Coulomb friction in the tangential direction (SAS 2010).

Table 1 Specifications of models

\begin{tabular}{lllll}
\hline $\begin{array}{l}\text { Compressive strength } \\
\text { of concrete }(\mathrm{MPa})\end{array}$ & Type of column & $\begin{array}{l}\text { Distance of batten } \\
\text { plates }(\mathrm{mm})\end{array}$ & Distribution of axial loads & Model name \\
\hline- & Hollow & 500 & Steel section & B-1 \\
- & Hollow & 250 & Steel section & B-2 \\
- & Hollow & 250 and $500^{\mathrm{a}}$ & Steel section & B-3 \\
20 & Concrete filled & 500 & Steel section & C-1-S-200 \\
20 & Concrete filled & 250 & Steel section & C-2-S-200 \\
20 & Concrete filled & 250 and $500^{\text {a }}$ & Steel section & C-3-S-200 \\
60 & Concrete filled & 500 & Steel section & C-1-S-600 \\
20 & Concrete filled & 500 & Entire section according to stiffness & C-2-E-200 \\
20 & Concrete-filled & 250 & Entire section according to stiffness & C-3-E-200 \\
20 & Concrete filled & 250 and 500 & Entire section according to stiffness & C-1-E-600 \\
60 & Concrete filled & 500 & Entire section according to stiffness & C-1-E10-600 \\
60 & Concrete filled & 500 & $10 \%$ concrete section and 90 \% steel section & C-1-E30-600 \\
60 & Concrete filled & 500 & $30 \%$ concrete section and 70 \% steel section
\end{tabular}

${ }^{\text {a }}$ The distance between the first three battens from the bottom is $250 \mathrm{~mm}$ and the other batten plates placed at each $500 \mathrm{~mm}$ 


\section{Material properties}

The stress-strain behavior materials of concrete core and steel sections are shown in Fig. 1a, b, respectively. It should be noted that the multilinear isotropic stress-strain curve for ordinary concrete is computed with the equation proposed by MacGregor (1992), and for high-strength concrete is computed with the equation proposed by Popovics (1973). The elastic modulus of concrete for ordinary concrete and high-strength concrete is defined by Eqs. 1 and 2, respectively:

$E_{c}=5000 \sqrt{f_{c}^{\prime}} \quad(\mathrm{Mpa})$,

$E_{c}=\left(3320 \sqrt{f_{c}^{\prime}}+6900\right)\left(\frac{\rho}{2300}\right)^{1.5} \quad(\mathrm{Mpa})$,

in which $f_{c}^{\prime}$ is the compressive strength of concrete (Mpa) and $\rho$ is the density of concrete $\left(\mathrm{kg} / \mathrm{m}^{3}\right)$.

Material nonlinearity of steel was accounted for the analyses based on Von Mises yield criterion. The kinematic hardening rule was used to define the material property in these elements. The Willam and Warnke (1974) model was used to define the failure of concrete. The concrete failure criterion can be expressed as follows:

$\frac{F}{f_{c}^{\prime}}-S \geq 0$,

where $S$ is the failure surface which is expressed by five input parameters: ultimate uniaxial compressive and tensile strength, ultimate biaxial compressive strength, ultimate compressive strength for a state of biaxial compression superimposed on hydrostatic stress state and ultimate compressive strength for a state of uniaxial compression superimposed on hydrostatic stress state. The failure surface in principal stress space $\sigma_{\mathrm{zp}}$ close to zero is indicated in Fig. 2.

\section{Boundary conditions and loading pattern}

The boundary conditions and loading pattern of the models are illustrated in Fig. 3. Two loading conditions were considered: constant axial loads along with monotonic increasing lateral displacement and constant axial load

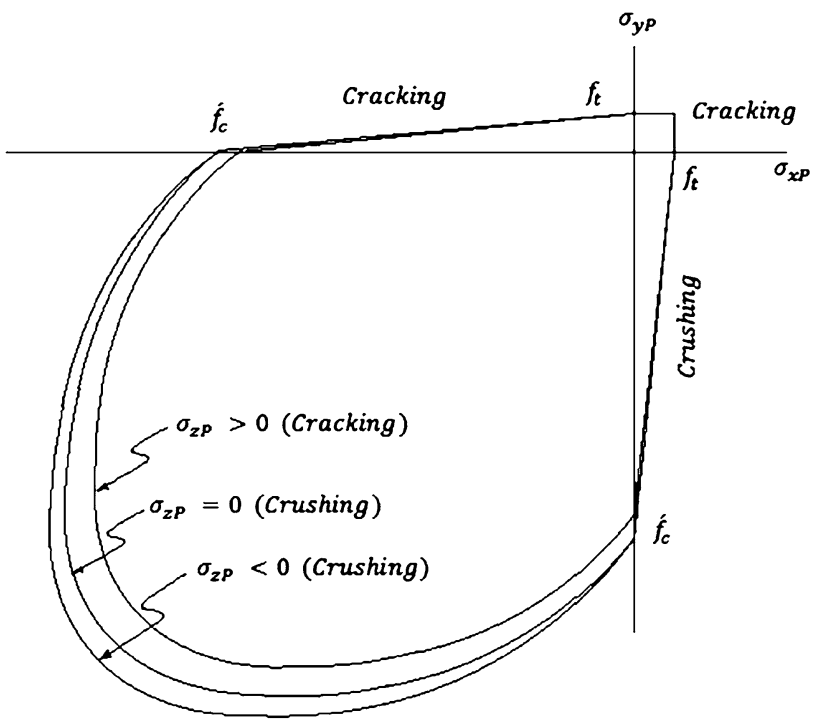

Fig. 2 Failure surface in the principal stress space close to zero (SAS 2010)

along with cyclic lateral displacement. To this end, a constant axial force of $350 \mathrm{kN}$ was applied to all of the models. Coincidentally, lateral cyclic displacement $(\delta)$ is applied to the top of the columns, as indicated in Fig. 3. It is worth mentioning that the parameter $\left(\delta_{\mathrm{y}}\right)$ in Fig. 3 is the lateral displacement of the yielding point of batten columns without concrete core. It should be noted that two independent conditions were considered for lateral loads: parallel to batten plates and perpendicular to them.

\section{Results}

Figure 4 indicates the pushover curves of the steel batten columns and CFBBC models. As indicated in this figure, the behavior of CFBBCs in which the axial load had just been applied to the steel chords was not acceptable. In such columns, both pre- and post-buckling performance was the same as those of built-up batten columns. Figure 4 also illustrates that even hollow batten columns with short distances of batten plates perform slightly better than
Fig. 1 The stress-strain relationship for the material

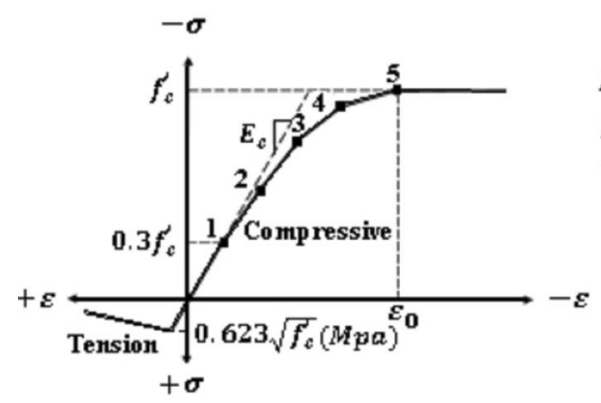

(a) Concrete

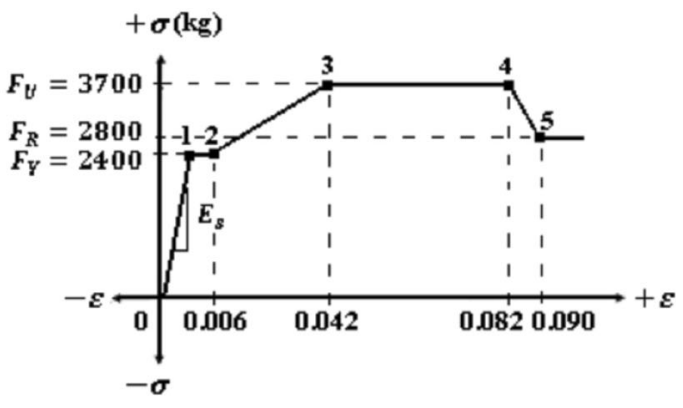

(b) Steel 
Fig. 3 Cyclic lateral loading history and loading conditions used in FEM

Fig. 4 Comparison of shear force-displacement curves in batten columns and CFBBCs
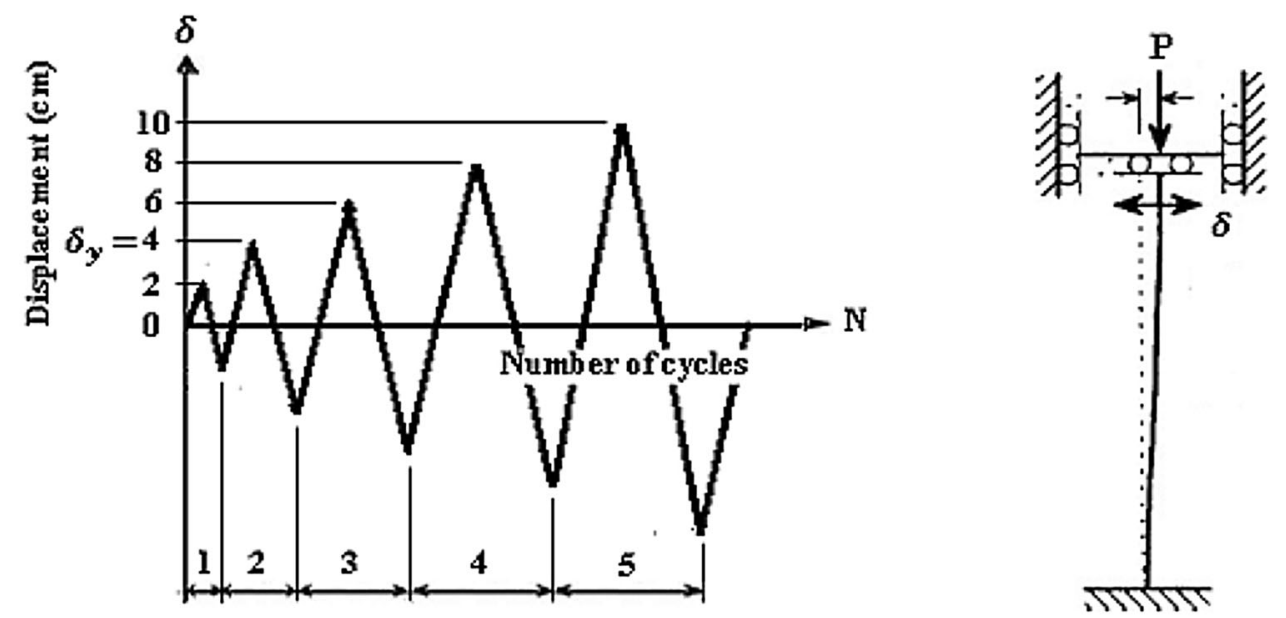

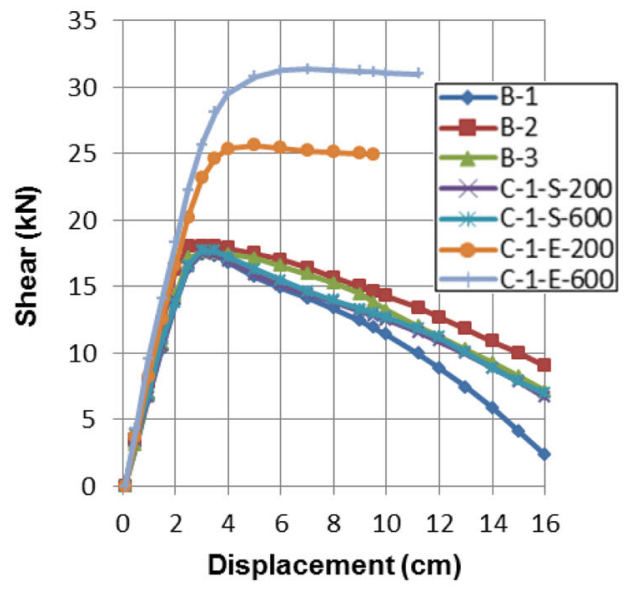

(a) Parallel to battens

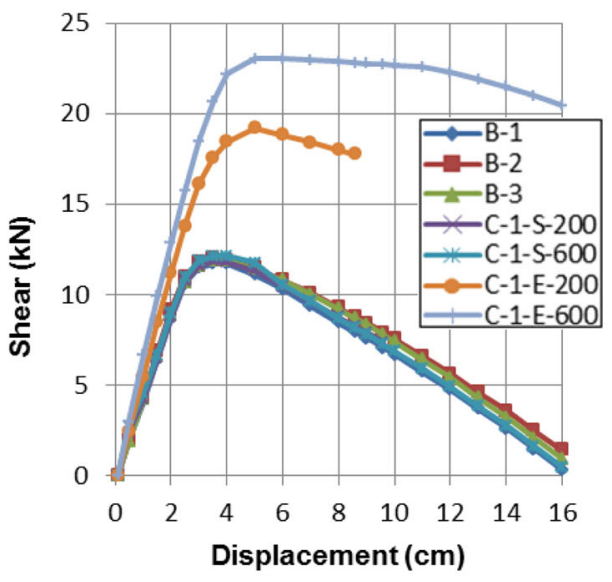

(b) Perpendicular to battens

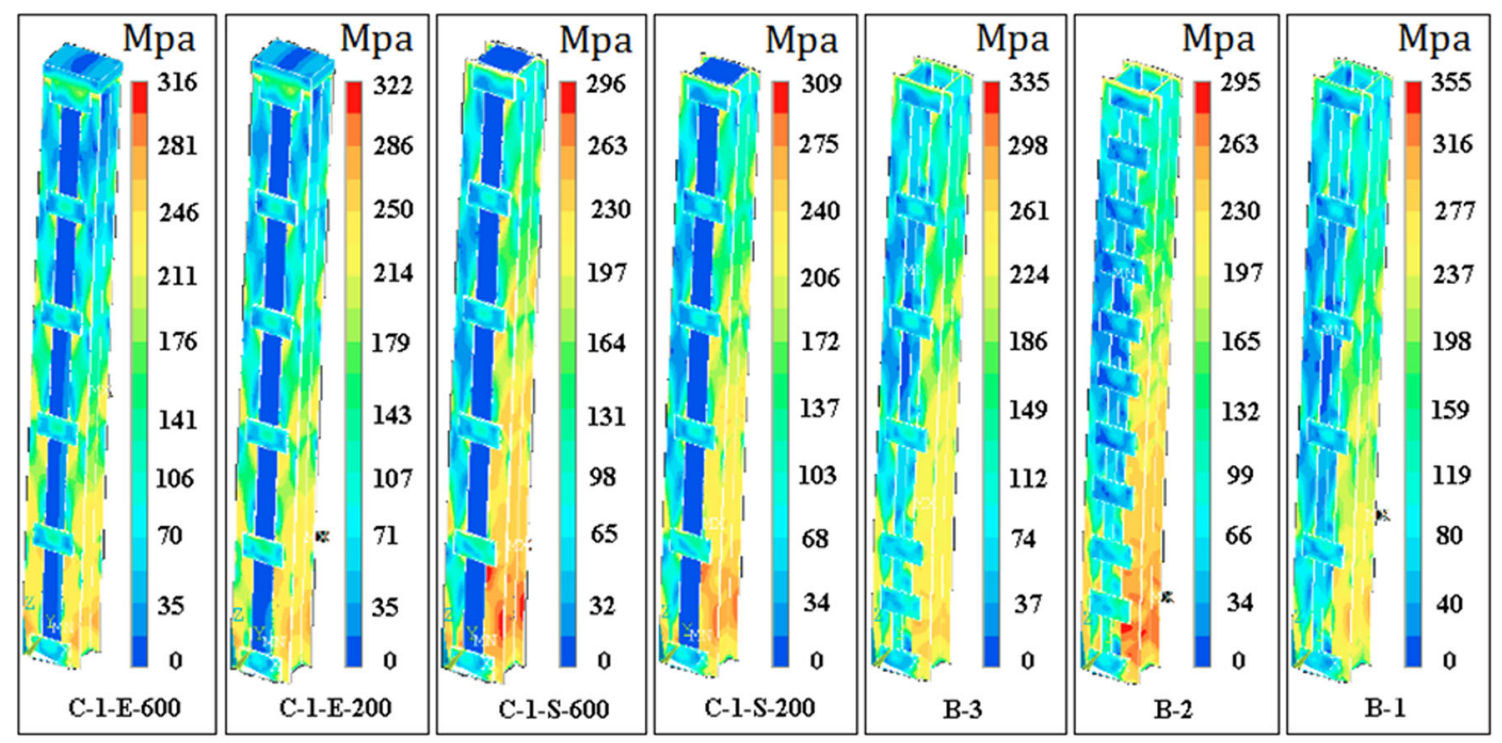

Fig. 5 Deformed shapes and Von Mises stress contours in the displacement to $9.5 \mathrm{~cm}$ and parallel battens 
Fig. 6 Shear forcedisplacement curves for different CFBBCs

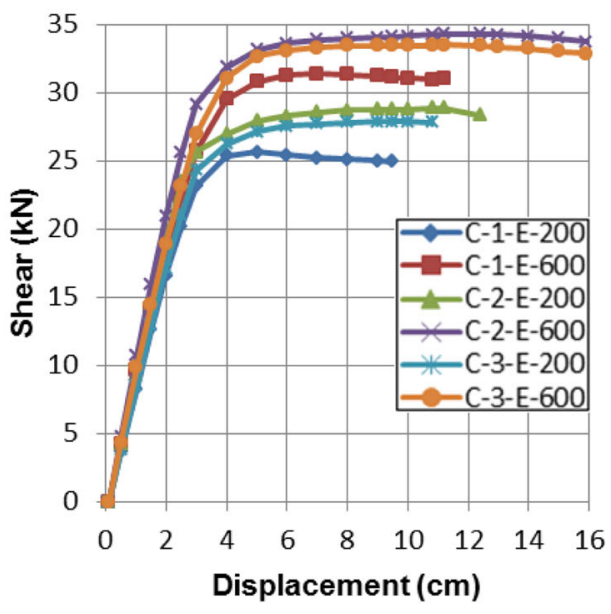

(a) Parallel to battens

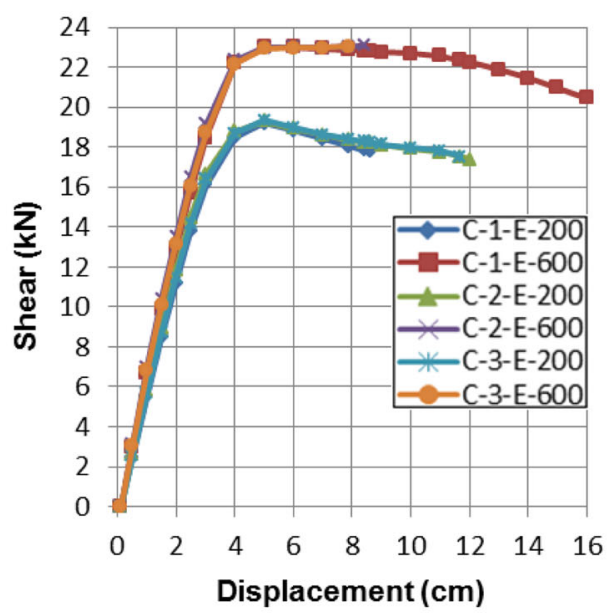

(b) Perpendicular to battens
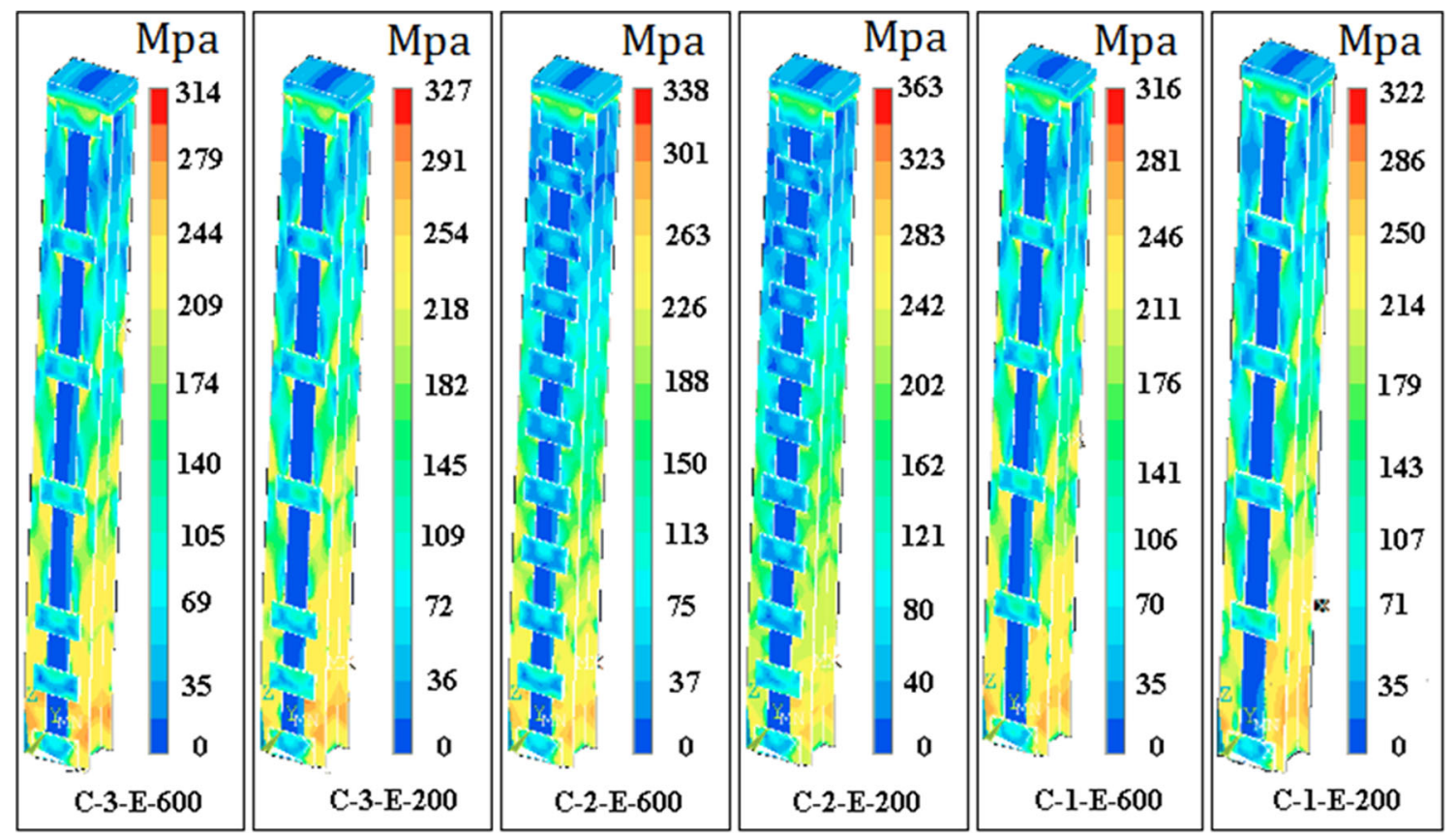

Fig. 7 Deformed shapes and Von Mises stress contours in the displacement to $9.5 \mathrm{~cm}$ and parallel battens

CFBBCs without axial load bearing of concrete core. It is obvious that in such a case, using high-strength concrete does not noticeably change the performance of CFBBC. Those CFBBCs in which the concrete core contributed to bearing axial loads, the behavior changed dramatically. Distribution of the Von Mises stress in column chords and batten plates is indicated in Fig. 5 .

Comparison of shear force-displacement behavior of CFBBCs and distribution of Von Mises stress on their deformed shapes are shown in Figs. 6 and 7, respectively. As illustrated in Fig. 6a, in CFBBC columns in which concrete cores contributed in bearing the axial load according to their stiffness, the buckling was not the major failure mode of the columns. Minor local buckling happened in some of the models after formation of plastic hinges. In locally buckled columns, the post-buckling behavior was rather stable. Concrete-filled batten columns with high-strength concrete cores had the highest ultimate strength. Variation of the compressive strength of concrete from 20 to $60 \mathrm{MPa}$ made 13-20\% change in the ultimate strength of CFBBCs. Furthermore, decreasing the spacing of batten plates at the bottom of the column increases the ultimate capacity of the columns by about $5 \%$. As indicated in Fig. 6b when the lateral loads are applied to the 
Fig. 8 The envelope curves of hysteretic loops

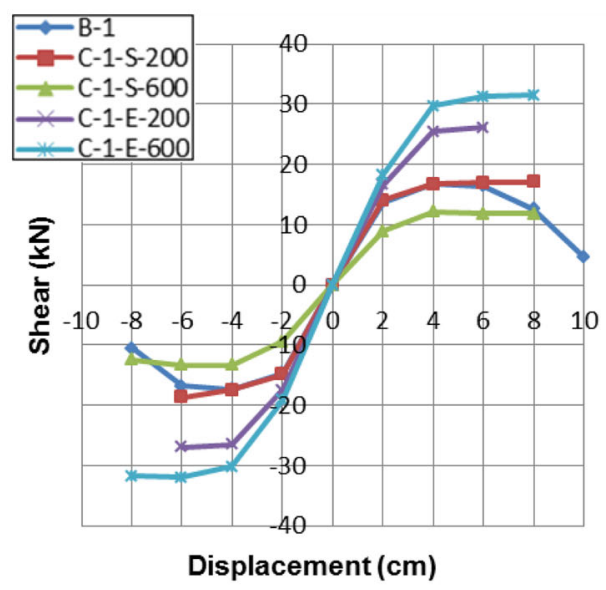

(a) Parallel to battens

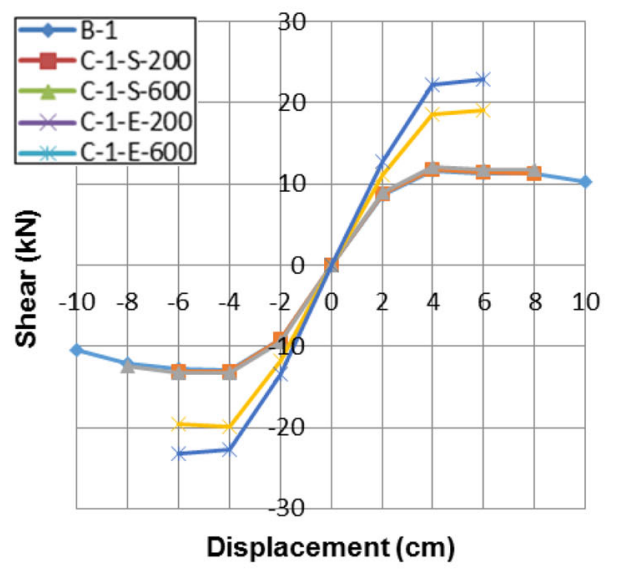

(b) Perpendicular to battens

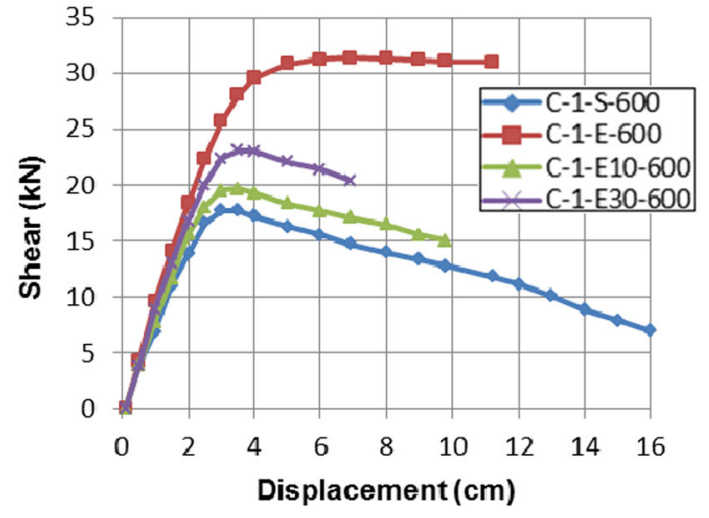

Fig. 9 Shear force-displacement curves, parallel to battens

column in a direction perpendicular to the batten plates, the spacing of batten plates do not have any contribution in the bearing capacity of CFBBCs.

Figure 8 shows the envelope curves of hysteretic loops for the batten columns with and without concrete cores. As illustrated in this figure, there is an observable load drop in envelope curve of the steel batten column. Such a drop happened because of buckling. It is observable in Fig. 8a that no drop happened in the envelope curve of the hysteresis loops of CFBBCs. In other words, even in CFBBCs without load carrying in the concrete core, the hysteretic behavior is noticeably more stable than that of steel batten columns. Figure $8 \mathrm{~b}$ shows that load-carrying cores had observable change in the hysteretic behavior of steel batten columns.

To investigate the effects of load carrying of the concrete core on the performance of the CFBBCs, the pushover curves of CFBBCs with different axial load carrying in concrete cores are compared in Fig. 9. As indicated in this figure, the ultimate strengths of the CFBBCs were noticeably increased by increasing the axial load carrying

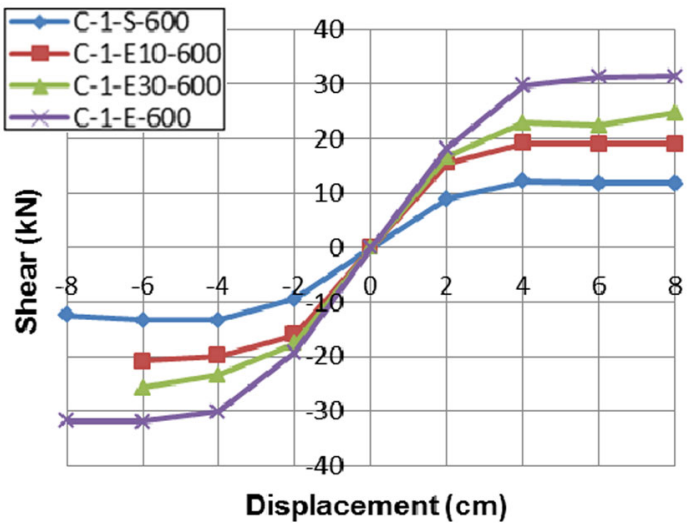

Fig. 10 The envelope curves of hysteretic loops, parallel to battens

of the concrete core. Furthermore, similar results were observable in the hysteretic behavior of these columns (See Fig. 10).

\section{Conclusions}

In this paper, parametric study on nonlinear performance of steel batten columns with and without concrete cores was conducted. To this end, nonlinear static analyses were carried out. Results of this study revealed that:

- Axial load-carrying concrete cores can increase the ultimate strength of the steel batten columns.

- Despite the steel batten columns in CFBBCs with axial load-carrying cores, buckling is not the major failure mode of the column.

- In CFBBCs with axial load-carrying cores, changing the compressive strength of concrete from 20 to 60 Mpa causes about 13-20\% increase in the ultimate capacity of the column. 
- The spacing of the bottom batten plates in the built-up batten columns with and without concrete core makes a noticeable contribution in ultimate capacity and hysteretic behaviors of columns.

Based on the results of this study, using concrete core would be a suitable approach for strengthening of the builtup batten columns. But in implementation of this method, attention should be given to ensure that axial loads are distributed between both steel chords and concrete cores.

Acknowledgments The authors would like to appreciate $\mathrm{Mr}$. Emamisaleh of QIAU for his valuable support.

Open Access This article is distributed under the terms of the Creative Commons Attribution 4.0 International License (http://crea tivecommons.org/licenses/by/4.0/), which permits unrestricted use, distribution, and reproduction in any medium, provided you give appropriate credit to the original author(s) and the source, provide a link to the Creative Commons license, and indicate if changes were made.

\section{References}

Cai J, He Z (2007) Eccentric-loaded behavior of square CFT columns with binding bars. J Build Struct 4:004

de Oliveira WLA, De Nardin S, de Cresce El ALH, El Debs MK (2010) Evaluation of passive confinement in CFT columns. J Constr Steel Res 66(4):487-495

Eshghi S, Zare M, Asadi K, Razzaghi M, Ahari M, Motamedi M (2003) Reconnaissance report on 26 December 2003 Bam earthquake. International Institute of Earthquake Engineering and Seismology (IIEES), Report in Persian

Hosseini Hashemi B, Jafari MA (2009) Experimental evaluation of elastic critical load in batten columns. J Constr Steel Res 65(1):125-131

Hosseini Hashemi B, Jafari MA (2012) Evaluation of Ayrton-Perry formula to predict the compressive strength of batten columns. J Constr Steel Res 68(1):89-96

HosseiniHashemi B, Hassanzadeh M (2008) "Study of a semi-rigid steel braced building damaged in the Bam earthquake". J Constr Steel Res 64:704-721

HosseiniHashemi B, Jafari MA (2004) "Performance of batten columns in steel buildings during the Bam Earthquake of 26 December 2003". J Seismol Earthq Eng 5(4):101-110

Hosseinzadeh NA (2004) Lessons learned from steel braced buildings damaged by the Bam Earthquake of 26 December 2003. JSEE J Seismol Earthq Eng 5(4):111-121

MacGregor JG (1992) Reinforced concrete mechanics and design. Prentice-Hall Inc, Englewood Cliffs

Popovics S (1973) A numerical approach to the complete stresstrain curve of concrete. Cem Concr Res 3(5):553-599

Razzaghi MS, Jafari MA, Ahmadpour HA (2010) "Seismic performance of steel build-up batten columns". In: Proceedings of the 9th U.S. National and 10th Canadian Conference on Earthquake Engineering, Paper No.1327, Toronto, Canada

SAS (2010) ANSYS 12.0.1 Finite Element Analysis System, SAS IP, Inc

Willam KJ, Warnke EP (1974) "Constitutive model for triaxial behaviour of concrete," Seminar on Concrete Structures Subjected to Triaxial Stresses, International Association of Bridge and Structural Engineering Conference, Bergamo, Italy, pp 174 